camphor mixture, which did not produce the desired effect; the dose was repeated about two hours afterwards, and in a short time she fell into a comfortable sleep, and awoke perfectly calm and composed. From this time there was not a single unfavourable symptom, the pulse never exceeding 90 , and seldom so quick, and little or no fever. The bowels were regulated by gentle aperients ; the diet for the first fortnight consisted of gruel and chicken broth; she was then allowed to take a small quantity of animal food in substance every day, abstaining from wine, beer, and everything of a stimulating quality. The ligature did not come away until the loth of October; the tumour is now entirely gone, and, I am happy to add, Miss S. is perfectly well.

\section{CASE OF EXHAUSTION}

\section{WITHOUT AN}

\section{APPARENT SUFFICIENT CAUSE.}

By Jonathan Toogood, Esq.,

Senior Surgeon to the Bridgwater Infirmary.

A lady who had been confined about four months, and partially suckled her child in one breast only, was apparently in good health, until she heard some distressing news which agitated her a good deal. Her menstruation had returned in the usual way a fortnight before this event, since which she had occasionally been subject to slight discharge. A day or two after this fright she was seized with coldness, trembling, and slight faintness, which were soon removed by a cordial. Ten days after this she was attacked with pain in the bowels after an evacuation, and faintness, which continued long enough to excite some apprehension in the minds of her friends. She remained in a faintish state from two o'clock in the morning until seven in the evening, when I saw her, in consultation with her usual medical attendant. I found her lying on her back with a blanched countenance, and a surface of death-like coldness, without any pulse at the wrist. There was sickness, with occasional attempts to vomit, and pain in the forehead, which was kept constantly wetted at her request. I learned that, notwithstanding cordials had been administered, very little effect was produced by them, and that she constantly relapsed into the same state; I got down a good quantity of hot brandy and water, after which a feeble pulsation was felt at the wrist for a few moments, and although brandy, opium, ammonia, and every other restorative which could be given, were freely and unremittingly administered, her state became more alarming. If the pulse was perceptible after a large dose of brandy and opium, it sunk again immediately, the faintness increased, she constantly called for the smelling-bottle and fan, and became so restless that it was scarcely possible to keep her still; the surface was bedewed with a clammy sweat, the respiration was short and cold, and she either refused to swallow any thing, or instantly made an effort to reject it. Notwithstanding the extreme coldness of the surface, she objected to all external heat, which seemed to increase her faintness. She remained in this alarming state until two o'clock the following morning, after which time she became more tranquil, took nourishment, and retained it. During the next twelve hours she gradually but very slowly recovered some heat and steadiness of pulse, but was not able to be moved or undressed until thirty-four hours after the attack.

There does not appear to have been sufficient cause for the extreme and protracted state of exhaustion which occurred in this case. There was no undue lactation, for that had been imperfectly carried on, and but for a short period, nor was there any other drain to weaken her powers. It seemed like one of those sudden attacks of faintness which sometimes occurs without any warning after a small bleeding, which, as far as my experience goes, is protracted and alarming. It brought to my recollection the aphorism of Hippocrates, which, however, is more applicable to diseases of the heart, which there was no reason to suspect in this instance. Qui crebro et fortiter absque causâ manifestâ liquentur animo, derepente morientur."

Bridgwater, March, 1842.

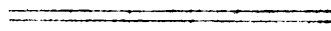

\section{CA S E}

OF

\section{PENETRATING WOUND OF BOTH LUNGS RECOVERY.}

TO THE EDITORS OF THE PROVINCIAL MEDICAL AND SURGICAL JOURNAL.

Gentlemen,-Althongh the old doctrine, that wounds of both lungs must produce immediate death, has been long exploded, still, " in this piping time of peace," so few medical men can have an opportunity of witnessing a case of the kind, that you may deem one which occurred in my practice not uninteresting to the profession. I give it from notes taken hastily at the time. The subject of the injury was young, healthy, and vigorous, which enabled me to carry venesection to the utmost limit, and to the early and active adoption of that remedy I principally attribute his recovery.

$$
\text { I remain, }
$$

Your obedient servant, A. N. RupDocx,

Bristol, March 28, 1842. Surgeon to the Police Force.

I was.called up early on the morning of Thursday, May 10, 1838, to see police-constable 199, Silas Perrott, aged 22, who was represented to have been seriously wounded whilst on duty. It appeared that, between three and four o'clock, a.m., he had detected a housebreaker robbing some premises which stood alone and in a very retired situation. The policeman attempted to take the man into custody, which he strenuously resisted, and a struggle of half an hour's duration ensued, during which time the latter, who had much the advantage of the policeman in point of height and strength, attempted to throw him into a river, which was the bonndary of the garden; and at length, finding he was likely to be captured, he drew from a case a long knife with a wooden handle, similar to that used by shoemakers, and gave the constable two desperate stabs in the body. The man eventually succeeded in getting away, leaving the policeman totally incapable of moving. In this state he was found soon after four o'clock, by the sergeant going his rounds, and with other assistance he was carried to the station-house.

I saw him between five and six o'clock; he was tolerably collected, but in a state of extreme exhaustion, from the combined circumstances of the severe nature of his wounds and the consequent loss of blood, which I found to have been considerable, and from the desperate struggle in which he had been engaged; a considerable quantity of frothy blood was passing from his mouth; he had great difficulty of breathing, with constant cough, and a very small pulse varying from 140 to 150 .

On examining the chest on the right side, I found a penetrating wound of rather more than an inch in width between the seventh and eighth ribs, about four or five inches below, and in a direct line from, the axilla; air was passing freely through the wound, 
and there was considerable emphysema. On the left side there was a corresponding wound, also, between the seventh and eighth ribs, but higher up and more posterior, situate almost in a direct line from the inferior angle of the scapula; very little air had escaped into the cellular membrane, but on passing the hand over the latissimus dorsi, the air was felt crackling under a considerable portion of that muscle. No doubt could exist as to the lungs being wounded on both sides, and I considered the prognosis as unfavourable as it could well be. As there was no fracture of the ribs, and the wounds were clean, I closed them both with adhesive plaster, applied warmth to the extremities, as he was shivering with cold, and administered some tea.

By nine o'clock, a.m., reaction had taken place; at ten o'clock his pulse had become tolerably steady at 120. Venesection to twenty ounces, which produced faintness; ordered a mixture of spermaceti and ipecacuanha wine to be taken once in three or four hours; to take nothing of any kind except tea and toast and water.

At three, p.m., he was labouring under more severe symptoms; his breathing was much oppressed; he had a good deal of pain and uneasiness about his chest, with a full pulse. Venesection to thirty-four ounces, which made him faint, and on recovering he expressed himself as much relieved.

At nine in the evening his symptoms were again aggravated, but not to so great an extent; his pulse had acquired so much firmness and strength that another blood-letting was readily foreseen, if not then absolutely necessary, and I took thirty ounces before he was faint; I ordered him ten grains of opium and soap pill, and left him for the night, with strict orders to be called if the symptoms returned.

I saw him on Friday morning at six o'clock; he had passed a tolerable night, and his state presented no symptoms which demanded interference. As I was desirous of obtaining some information about the wounds of the lungs, I removed one strip of plaster, and found that the air was passing with much less freedom than twenty-four hours ago, although the external wounds, in consequence of the continued oozing of blood, were not healing by the first intention. The wounds were again immediately closed; one ounce of castor oil was administered. Mr. R. Smith, the senior surgeon of the infirmary, saw him to-day; he considered he would have a hard struggle for it, and recommended a small abstraction of blood in the evening.

Eight, p.m. Has continued up to this time pretty much as in the morning; bowels relieved. I bled him to ten ounces; repeated the opium pill.

Saturday morning. He has passed a tolerable night again, and is free from pain; pulse soft, but quick. He takes the spermaceti mixture, from which he says he finds much relief and comfort. No air whatever passes through the wounds.

Sunday morning. He remains in a quiet state; the giant has evidently been conquered since Thursday evening. The external wounds are not at all disposed to heal, but those of the lungs are apparently closed. Allowed a small teacupful of thin bread and milk, which is the first food he has taken.

From this time he slowly but gradually progressed, and he left his bed about three weeks after the injury. The bloody expectoration continued for five or six days, and the emphysema gradually subsided. The wound on the right side of the chest did not heal for a month. Adhesion of the pleura on the right side has taken place to a considerable extent, covering a space as large as the hand; on the left side the state of the parts is not so easily ascertained, owing to the thick layer of muscle.

He subsequently was blistered, and took iodine for some time. He remains in the force on reserve duty, which does not expose him to cold or wet. He has had several attacks of shortness of breathing and pain in the side, but they have all given way to a day's confinement in bed, and a mixture of tartar emetic These attacks have latterly been less frequent. $\mathrm{He}$ has got married, and at the time of my writing this he tells me his health has much improved within the last twelvemonth.

\section{CASE OF PURPURA,} WITH

\section{DESTRUCTIVE DISEASE OF THE ANCLE-} JOINT.

By F. A. Bulley, Esq.,

Surgeon to the Royal Berkshire Hospital, Reading.

On March 14, 1842, I attended the inspection of the body of a poor boy, 17 years old, who had died the day before, from a disease of the ancle-joint, for which he had been treated seventeen weeks, and, as far as I could learn, his complaints had existed for some time prior to that time. His case not having been under my immediate care, I am unable to detail its progress ; but the patient seemed to be of a highly scrofulous constitution, and of a very delicate frame of body, and had latterly become hectic, and greatly emaciated by his disease. Some time ago, before his health had become too much affected by the local disease, amputation had been proposed to him; but to this he obstinately refused to assent, and it was observed that he became worse after the proposal had been made, from the effect the fear of it had upon his enfeebled nervous system, which, naturally weak, had become weaker through the wearing nature of his complaints. Latterly his legs had become nearly covered with minute purpurous spots, as well as the surface of his body, where there were some petechial stains, but not nearly so numerous or distinct as on the extremities.

Inspection.-The lungs were of a healthy appearance externally, and there was no appearance of any tubercular disease of their structure. They were somewhat darker coloured than natural, from congestion of their vessels. There was rather more fluid than common in the pericardium. The heart was preternaturally small, not exceeding in bulk that of a child of six years' old; but it did not present the shrivelled and wrinkled appearance of its exterior, described by $\mathrm{Dr}$. Hope, to indicate that it had ever been of greater size. The auricles were somewhat dilated, and, together with the ventricles and large vessels emanating from the heart, were filled with dark-coloured fluid blood, which, when removed, had an unhealthy, treacly appearance, and seemed to have entirely lost its power of coagulating. The muscular structure of the body was pale and wasted. There were no appearances of petechial spots on any part of the serous tissues of the thoracic or abdominal cavities or viscera.

Examination of the Diseased Ancle.-On the inner side of the leg, over and just above the ancle-joint, there were two or three ragged openings of a dark black colour, from which, during life, had flowed a dark-coloured ichorish fluid, but no pus. From these openings a probe could not be directly introduced into the cavity of the joint, owing to their not being immediately placed over the apertures in the capsular ligament, but by passing it underneath the skin for a short distance through the disorganised cellular tissue, the opening was readily discovered; the distance of the subcutaneous passage was, of course, greatest in those openings farthest from the joint. The integument over the inner projecting surface of the internal unciform bone was rather more dark-coloured than the rest, and an aperture in the skin over it was somewhat larger than the others, and through this a 